\title{
Organizational Training Modalities: Investigating the Impact of Learner Preference on Performance
}

\author{
Tyechia Paul \\ Dept. of Management, Hampton University \\ 100 E. Queen St. Hampton, Virginia 23668, United States of America \\ Email: tyechiapaul@gmail.com
}

Received: June 28, 2016 Accepted: July 17, 2016 Published: July 28, 2016

doi:10.5296/ijld.v6i3.9679 URL: http://dx.doi.org/10.5296/ ijld.v6i3.9679

\begin{abstract}
Employee training is a strategic business investment, a manifestation of firms' commitment to improve service, operations, career development, and employee performance. Traditionally, training has been delivered in a face-to-face format. However, new training modalities of e-learning and mobile learning have emerged. Managers and workforce training professionals often face the challenge of selecting training modes that are economical, convenient, effective, and in the format preferred by the employees. The objective of this study was to evaluate whether learner preference for a training modality impacts the learners' training performance.

A group of 103 study participants completed a workforce training module in one of three training modalities, face-to-face, e-learning, and mobile learning. Study participants completed a four-step experiment, which included a pre-assessment, training intervention, post-assessment, and survey. The research showed that although there was an interaction between training preference and training method on post-assessment performance, there was no significant difference in the training performance of learners who were trained in their preferred method versus those who not trained in their preferred method. This indicates that organizational training and development professionals should base their decision on other factors.
\end{abstract}

Keywords: Training, E-learning, Mobile learning, Workforce development, Preference, Organizational training, Employee training, Human resource development 


\section{Introduction}

Development of a well-trained workforce is a human capital investment activity that has always been a priority of management. This commitment has been substantiated by the fact that U.S. companies spent over $\$ 70$ billion for training in the United States and $\$ 130$ billion on training their employees globally (Bersin, 2014). Managers have faced the problem of determining which training delivery method is most viable for the firm, and which will attain the most learner participation. Learners often indicate very strong preferences for one training method over others. The three training delivery methods examined in this study were face-to-face training (FTF), e-learning, and the newest training delivery method, mobile learning (American Society for Training and Development, 2006).

The research objective was to assess whether learners' training modality preference impacts their training performance. Learning was measured using pre- and post-training assessments that evaluated students' performance throughout a course (Walvoord, 2010). Learner preference was measured by subjects' survey responses. The research design was an experiment in which a common training module was executed with three groups and developed under accepted instructional design methods.

The research objective was to measure training performance among learners grouped by training preference. Learners were surveyed to indicate whether they preferred to receive training via e-learning, mobile learning, or FTF training. For the purpose of this study, e-learning is defined as a self-paced electronic learning module taken on a stationary personal computer without the involvement of a live instructor. Such modules may include video, assessment questions or other interactivity in a computer interface that provides immediate feedback. There is no external party evaluation required (Welsh, Wanberg, Brown, \& Simmering, 2003). Mobile learning is defined herein as e-learning taken via smartphone, laptop, or tablet (Kansas State University, 2013; Moore, 2011), and face-to-face training (FTF) is live training delivered with the learners and instructor in a physical classroom setting (Gaither, 2009).

\section{Literature Review}

Organizational training and development has always been a priority of management. Wang, Sun, Li, and Xuejun (2008) discussed the needs gap that remains after companies hire qualified employees. After selecting employees with satisfactory and even exceptional levels of formal education, employer-provided training is still necessary. Formal schooling from traditional universities provides students with the general knowledge and transferable skill sets that are portable to many employers. Yet, most employers still require firm- and industry-specific skills that cannot be provided by such general training. The dynamic technological environment and organizational change make ongoing employer-provided training necessary. In the labor market, employer-provided training can be substituted for traditional schooling. Employees can achieve the same degree of occupational skill with less formal schooling and more on-the-job training or vice versa (Wang, Sun, Li, \& Xuejun, 2008). 


\section{Macrothink}

Workforce training and development has been a major commitment for corporations that comes at a high cost. The Association for Talent Development (ATD) estimated in its 2013 State of the Industry report that organizations spent $\$ 164.2$ billion on employee training in 2012, up from $\$ 125.9$ billion in 2009 (Stern, 2011). Of the 2013 training expenditures, $61 \%$ or $\$ 100.2$ billion was spent internally. Twenty-eight percent, $\$ 46$ billion, was spent procuring external training services, and the remaining $11 \%$, or $\$ 18$ billion, was spent on employees' tuition reimbursement (ATD, 2013). See Figure 1. Bolman and Deal (2008) evaluated the importance of training by examining the other end of the spectrum, the untrained worker. They described untrained and undertrained employees as harmful to the organization in four ways: "shoddy quality, poor service, higher costs, and costly mistakes" (Bolman \& Deal, 2008, p. 148).

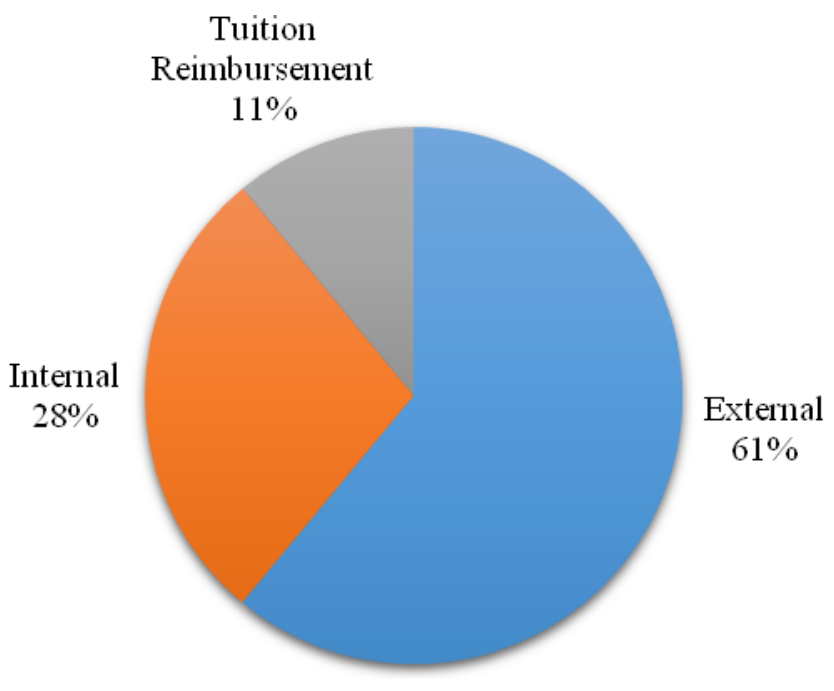

Figure 1. Organizational Training Expenditure

Organizations have become so committed to employee development that many, like Caterpillar Inc., Bell Atlantic, DLA Piper, Merrill Lynch, and Boeing, have implemented internal corporate universities (Blass, 2005; Paul, 2014). These universities exist within organizations' training departments. Training departments are responsible for managing the development, acquisition, and delivery of employee training. They must do so despite limited budgets, varying learner preferences, and often a geographically dispersed workforce (Welsh, Wanberg, Brown, \& Simmering, 2003).

\subsection{Benefits of a Well-Trained Workforce}

Organizations can minimize turnover and optimize performance by offering professional development opportunities, including training (Kelley, 2014). One critical factor driving employers to offer more training has been the decreasing shelf life of knowledge due to organizational, industrial, economic, and technological change. In some industries, the shelf life of knowledge is just one to two years. This generates the need for not only one-time new hire training, but also ongoing workforce training. Existing and prospective employees find employer-provided training and formal corporate universities desirable, and it creates for the 
firm a reputation of being an employer of choice in their respective industry (Meister, 1998). Companies have used their investment in employee education as evidence of their competitive advantage because they are able to recruit, develop, and retain the best and brightest talent (Meister, 1998). According to the American Supply Association (2008), other strategic reasons firms cited for providing training include improving profitability, sustaining competitive advantage, aligning employee skills and behaviors to strategic initiatives, minimizing turnover, and increasing sales.

Electronic learning has emerged as a substitute to traditional FTF training. Electronic learning allows managers to deliver consistent training content quickly to a large, geographically dispersed workforce (Welsh, Wanberg, Brown, \& Simmering, 2003). This method of training delivery has proven to be much less expensive than the FTF training that firms have historically offered their employees (DeRouin, Fritzsche, \& Salas, 2005).

\subsection{Training as Human Capital Development}

Organizations are willing to invest in training, understanding that it can be difficult to precisely measure the return on investment (ROI). For manufacturing and sales companies, ROI can be measured by a change in the number of units produced or accounts created as a consequence of employee training. For example, an internal study at Motorola identified ROI of $\$ 29$ for each dollar invested in sales training (Bolman \& Deal, 2008). In this increasingly knowledge-based economy, professional service companies find it difficult to measure return on investment for training because doing so would require the isolation of training as the sole independent variable influencing changes to profit (Stern, 2011). When the company's product is less tangible, as in knowledge-based or professional service companies, it is difficult to quantify ROI in a manner meaningful to that organization (Phillips, 2003). According to Bill Stetar founder of Performance Technology Group (2003), "There is no other workplace issue on which so much money is spent with as little accountability as training" (Barron, Berger, \& Black, 1999, p.6). Despite the challenges with quantifying ROI of training, companies still recognize its value.

Barron, Berger, and Black (1999) established that the value of training has been found in its effect on employee wages, productivity, and competitive advantage. They examined the relationship between starting wage, wage growth, and productivity growth. In their study, they found a weak correlation between wage growth and employee training, but a high correlation between productivity growth and training (Barron, Berger, \& Black, 1999). The effect of one hour of training on productivity growth is five times larger than its effect on wage growth (Wang, Sun, Li, \& Xuejun, 2008). Lundquist (2009) found that when a sample of legal secretaries at U.S. firms completed employer-provided document production training, their rate of proficiency increased by $48 \%$. Lundquist estimated that following assessment and targeted employee training, firms can realize a cost savings of $\$ 755,685$ after the first year. This savings estimate was a function of fewer salaries, less time lost formatting documents, fewer overtime hours, fewer calls to the Help Desk, and reduced document corruption (Lundquist, 2009).

Organizations have been reevaluating the traditional FTF training delivery method. For 
example, Caterpillar University, the training and development unit of Caterpillar, Inc., reported a $40 \%$ cost savings between traditional instructor-led training and less expensive e-learning (Stacy \& Taylor, 2010). By implementing distance learning, the U.S. Army National Guard decreased training costs by $\$ 1.6$ million. Budget Rent-A-Car spent $\$ 2,000$ per learner for a two-week training course. After implementing a distance learning program, they reduced the cost per learner to $\$ 156$ for the same course. Bell Atlantic realized an ROI of $366 \%$ for its computer-based learning program. When Boeing deployed business strategy e-learning to 17,000 geographically dispersed managers, it realized an immediate costs savings of $\$ 9$ million in travel expenses (Burgess \& Russell, 2003).

New technologies offer innovative and cost effective ways to deliver enterprise-wide training programs. These new technological methods also provide the advantage of delivering training more consistently to all employees, ensuring the uniformity of the content delivered, increasing the ease with which training content can be updated, reducing travel costs, and providing on-demand training anytime, anywhere (DeRouin, Fritzsche, \& Salas, 2005).

\subsection{Face-to-Face Training}

Traditional FTF training is delivered to learners and led by an instructor in a physical location (Gaither, 2009). Chief Learning Officer Magazine surveyed chief learning officers across industries and determined that in 2014, for the first time, chief learning officers (CLOs) delivered more training with e-learning than with the traditional FTF method. The survey results revealed a decline in FTF training since 2010 and a significant increase in asynchronous and synchronous e-learning. In upcoming years, CLOs expect FTF training to represent a lessening percentage of their training portfolio, mainly due to the high cost of this training modality. Firms will adjust their training delivery methods based on convenience and cost (Anderson, 2014).

As Anderson (2014) reported, CLOs try to apply the right delivery method for the training content, of which there are two main types: business skills courses and information technology (IT) courses. Managers and their employees often prefer one modality over another for certain content, and overall, the preference for FTF has been declining. However, CLOs still see the value in FTF training for some business soft skills courses that require live, in-person interaction with instructors and peers (Anderson, 2014).

Between 2013 and 2014, FTF or classroom training decreased by 1.1\%, and e-learning offerings, both synchronous and asynchronous, increased from $28.7 \%$ to $32.6 \%$ of training offerings. Use of FTF training has been slowly decreasing while the use of e-learning has been rapidly increasing for workforce training. According to the same CLO magazine study, $57 \%$ of respondents preferred to offer business skills training via the FTF method, but only $29 \%$ preferred FTF delivery of technical training (Anderson, 2014).

Learners and their organizations have historically had a strong preference towards FTF training. While there have been some benefits, there are also several significant drawbacks to that modality. Learners get the benefit of receiving training in a classroom environment, away from the noise and distractions of their regular work area. FTF training allows learners to 
interact with one another and their instructor in a live, professional manner that other forms of training do not allow. For soft skills training, they can engage in role-playing activities that would be difficult to synthesize via e- or m-learning. Disadvantages of FTF training have included logistical challenges. In order to participate in FTF training, employees are essentially be removed from their regular work responsibilities for the duration of the training session plus any travel time to get to the training location. This reduces the volume of work that would normally be performed by employees during the time spent in training, and thus, temporarily decreases their productivity. It is also difficult to schedule FTF training at a time and location that will allow the target audience to attend. While receiving the training, employees are removed from the equipment, processes, and materials that they actually use in their jobs. However, for some types of training, it is more advantageous for learners to have access to those resources in order to gain hands-on experience during training (Business and Legal Resources, 2011).

Other disadvantages include the fact that no two FTF training sessions are the same. Learners have different questions and feedback, and the discourse of the session can digress. Even when the lecture is explicitly scripted, the live nature of the class makes the content of different sessions' discussions inconsistent, and time constraints make it difficult to cover all required content when digressions occur (Paul, 2014).

Face-to-face training instructors must often cram as much information as possible into one scheduled session in order to deliver the required information. This is because it is generally easier to schedule learners for one long training session, instead of multiple separate, although shorter, FTF training events (Paul, 2014).

The most substantial disadvantage to FTF training has been the excessive costs associated with that training modality. When companies offer FTF training, they incur the costs of instructor compensation, travel-related expenditures and reimbursements for instructors and learners, as well as indirect expenses associated with lost productivity and coverage for employees' time spent attending FTF training sessions (DeRouin, Fritzsche, \& Salas, 2005). Face-to-face training costs companies approximately $40 \%$ more than electronic training methods (Stacy \& Taylor, 2010).

\subsection{E-Learning}

According to Welsh, Wanberg, Brown, and Simmering (2003), there are many benefits of e-learning for organizational training. The advantages of offering e-learning include the ability to provide employees with consistent training globally, reduce the training delivery cycle time, maximize learner convenience, minimize information overload, and reduce expenses.

Organizations have often been required to offer regulatory training in order to remain compliant to the governing bodies within their industry or locale. Large organizations may find it very time consuming, costly, labor intensive, and overall difficult to deliver such training within the timeframe required by the regulatory body. For instance, the law firm DLA Piper has utilized e-learning to deliver required sexual harassment training biennially to 
all employees in California. The firm's management, realizing the value of the content, decided to exceed that state requirement and deliver the training to all employees nationwide as an e-learning module. By deploying as e-learning, the sexual harassment training was delivered their workforce nationwide quickly, consistently, compliantly and less expensively than live training (Paul, 2014). The e-learning benefits of speed, consistence, compliance, and cost-effectiveness are optimally realized when there is a large, geographically dispersed learner population and the training is required often (Welsh, Wanberg, Brown, \& Simmering, 2003). All three of these conditions were realized in the case of DLA Piper. The firm employs a workforce of approximately 3,000 across 30 offices nationwide. It adhered to a biennial delivery of the sexual harassment e-learning, including the performance of regular course updates to remain compliant (Paul, 2014).

Electronic learning allows learners to control both the duration and timeliness of the training without overwhelming them with a large volume of information at once. The just-in-time nature of e-learning allows learners to isolate and access the exact topics they need precisely when that information is needed. With e-learning, organizations can track learners' activity in the modules and their mastery of the skills therein by including quizzes and other engaging activities in the course. Organizations can track this activity by housing their e-learning modules and training records in internal learning management systems, which log learner access to the course, quiz scores, and completion status (Welsh, Wanberg, Brown, \& Simmering, 2003).

\subsubsection{E-Learning Studies}

The ROI Institute, surveyed Fortune 500 CEOs and leadership from among the top 50 privately held U.S. companies. These firms' e-learning expenditures ranged from $\$ 10$ million to $\$ 640$ million with an average expenditure of $\$ 138$ million. Seventy-six percent of survey respondents reported significant investment in e-learning. Twenty percent reported investing just the minimum, and four percent reported intentionally trying to avoid making such training investments. Top managers reported that the main additions they plan to make in their firms' organizational training and development programs are m-learning, followed by eand m-learning development tools. (Carruth \& Carruth, 2013).

Since e-learning can contain different types of media, instructional technologists and e-learning developers need to determine which combination of media should be incorporated in the e-learning in a cost-effective manner without diminishing its usefulness to the learner (Liu, Liao, \& Peng, 2005). Liu, Liao \& Peng found that media-rich e-learning, including audio, text, and video resulted in higher levels of concentration and higher levels of perceived usefulness in learners (Liu, Liao, \& Peng, 2005).

Selim (2005) examined four critical success factors (CSFs) of e-learning. He defined CSFs as things that must be done for a company to ensure successful deployment of e-learning. Selim's CSFs included instructor characteristics of attitude, teaching style, and control of technology. They included such learner characteristics as motivation, technical proficiency, interactive collaboration, and perceived effectiveness. The technology characteristics were reliability, richness, consistency, and infrastructure and service effectiveness at the 
organization. Lastly, Selim included among the CSFs organizational support characteristics, such as availability of technical support and reliability of hardware and software.

Tzeng, Chiang, and Li (2007) examined the effectiveness of e-learning and found the present e-learning evaluation criteria lacking. Their evaluation model, for the purpose of organizational learning, promotes the utilization of adult learning theory in the development and evaluation of all manners of training (Tzeng, Chiang, \& Li, 2007). Web design is a key component of e-learning since the learning management systems (LMS) containing the modules are usually housed on websites. These sites may be hosted internally as with UniversitySite and Blackboard LMS,on external websites like CustomGuide.com, or on external cloud platforms as with Canvas. Appropriate and useful design is important, both in the course and the LMS. They must be easily navigated, user-friendly, and fully functional (Paul, 2014).

Most e-learning is asynchronous, with a unidirectional information flow from the predesigned, prerecorded training module to the learner. E-learning can be more adaptive for the learner, within the developer's predetermined parameters. E-learners generally have the ability to start, stop, and resume the e-learning module as they wish. E- and mobile learners can take a break when they reach their maximum capacity of information retention for that period of time to avoid the information overload (Elwart, 2013) that can occur if learners lack autonomy over their training (Kruse, 2004).

In Rao's 2011 phenomenological study, survey participants were all experts in e-learning and organizational training and development across multiple industries. These respondents described "speed of delivery, cost effectiveness, uniformity of programs, updating and administering course content across the organization at a fraction of the cost and time compared to physical classroom learning as the driving force in implementing e-learning in their organizations" (Rao, 2011, p. 101).

According to Rao (2011), e-learning has emerged as a major differentiator amongst corporations to attract and retain the best talent, the source of competitive advantage. Among study participants, $67 \%$ felt that e-learning lacks the human touch that some learners expect, and many prefer, in learning environments. Those respondents felt that e-learning cannot provide opportunities for human interaction, debates, discussion, and knowledge sharing between learners and instructor. Advances in telecommunications and computer processing speeds have been able to better support multimedia e- and m-learning and improve the level of personal interaction among learners and instructors. Rao also suggested m-learning as an area of further research due to the fact that the technology is "very new and evolving" (Rao, 2011, p. 121).

Some studies have examined various aspects of e-learning delivery, but fewer have explored mobile learning. The ASTD (2013) published "Going Mobile" study about corporations' transition toward offering more mobile learning content, and Ally researched the evolution of e-learning to m-learning (2009). Since the two types of learning are so closely related, an e-learning study can easily be reproduced to explore m-learning. However, comparative studies are rare. 
Russell's No Significant Difference (NSD) Phenomenon (1999) demonstrated that there is no significant difference in learner outcomes regardless of the medium of training delivery. These findings supported the use of e-learning to obtain the same training result at a lower cost (Strother, 2002) than FTF training. In his book, Russell analyzed 355 studies published over 70 years on topics related to workforce training and education. One consistent theme was identified. "No matter what or who is being taught, more than one medium will produce adequate learning results and we must choose the less expensive media or waste limited educational resources" (Russell, 1999, p.viii).

The benefits of utilizing different media for training delivery have primarily been economic, and the training outcomes via different delivery methods have been found in numerous studies to be statistically similar. Russell's book was published prior to the widespread emergence of m-learning. Therefore, it does not include that training method. This study includes examination of m-learning for the purpose of workforce training. Despite finding no significant difference in training effectiveness, Russell identified some advantages to the technological modalities. Using technology for the delivery of training allows companies to increase efficiency, bridge distance, and circumvent obstacles (Russell, 1999).

O'Dell's 2009 study examined different generations' satisfaction with computer-based training. The 250-person sample included employees of various companies throughout North America and across industries, including energy, medical, education, sales, government, insurance, finance, and manufacturing that were members of the ASTD and E-Learning Guild. Respondents answered questions about the learner interface, learning community, content, and the level of personalization of the training module. Among the four generations, Traditionalists, Baby Boomers, Generation X, and Millennials, the study confirmed no significant difference in mean satisfaction (O'Dell, 2009).

\subsection{Emergence of M-Learning}

Mobile learning has emerged as the next big wave in education for both companies and educational institutions (Abas, Peng, \& Mansor, 2009). The use of e-learning, especially in organizations, outpaces the current academic research on the topic (DeRouin, Fritzsche, \& Salas, 2005). There has been little formal research or exploration into m-learning as a method of training delivery.

Mobile learning is a new, highly specialized niche subset of e-learning. This creates the need to bring research up to the speed of practice. M-learning will continue to increase in popularity (Welsh, Wanberg, Brown, \& Simmering, 2003). "Mobile devices are irrevocably changing corporate learning. The physical classroom and its virtual surrogate, the webinar, are not going away. Nor will formal e-learning courses disappear" (Roberts, 2012). Yet this "mobile explosion" requires corporate training professionals to rethink their course offerings and training delivery methods to create new learning content for delivery via mobile device (Roberts, 2012). Roberts (2012) suggested four best practices for designing mobile learning:

1. Divide training content into small segments.

2. Study learner interact with the training modules, and seize opportunities for 
just-in-time learning.

3. Integrate social technologies to foster peer-to-peer learning.

4. Apply video gaming principles to foster increased learner engagement. (Roberts, 2012).

\subsubsection{M-Learning Studies}

A recent ASTD survey determined that $57 \%$ of respondents predicted that their organizations would design training for delivery on mobile devices within the next three years. However, a mere $15 \%$ of respondents' employers were currently using mobile learning. The following year's survey revealed a dramatic increase. Then, $28 \%$ of percent of respondents confirmed that their organizations offer mobile learning. That ASTD report indicated that $59 \%$ of respondents developed mobile learning content internally in contrast to the $32 \%$ that procured mobile learning products and services externally (ASTD, 2013).

Survey respondents reported barriers to their implementation of mobile learning, depicted in (American Society for Training \& Development, 2013). However, such barriers are applicable to almost any business function. They included budgetary constraints; security, legal, and policy concerns; lack of suitable IT infrastructure to support the new technology; and difficulty integrating into the LMS (ASTD, 2013).

Despite the perceived barriers to implementation, there were strong correlations between mobile learning formats, learning effectiveness, and market performance (ASTD, 2013). Most of the workforce development experts surveyed were "optimistic that mobile technologies will improve their organizational learning in coming years" (ASTD, 2013, p. 8). The vast majority of respondents, $89 \%$, reported that mobile technology would improve learning in their organization from a moderate to a very high extent (ASTD, 2013).

In 2011, the U.S. Air Force tested the usefulness of three different mobile devices to provide a blended method of delivering the supplemental materials for technical training. They incorporated the iPod Touch, the HTC Touch Pro (smartphone), and the ASUS Eee Netbook (laptop). These devices were tested in Air Force Aerospace Ground Equipment (AGE) Apprentice courses, which teach aircraft maintenance personnel how to maintain and repair AGE (Moore, 2011).

The research sample consisted of 160 students in 16 classes at Sheppard Air Force Base in Texas. The devices were used to access course materials, including PowerPoint presentations, reference guides, diagrams, and in some cases to take notes and record video of lectures. Internet access was precluded from these devices. Quantitative data was collected via mid-course and final exams. Qualitative data was gathered through surveys given to both students and instructors to capture demographics, ease of use, satisfaction rates. Moore hypothesized that there was no significant difference between average test scores in each of the classes using digital devices and the control group, which was taught via face-to-face instruction, but received no device (Moore, 2011). The t-tests showed no significant difference between baseline and control group test scores in all but one class. Learners 
indicated similar levels of satisfaction for iPods and smartphones, but netbook users had higher levels of satisfaction than the users of other devices (Moore, 2011).

Williams (2009) examined the effectiveness of m-learning versus face-to-face (FTF) learning. The study sought to determine the effectiveness of each learning medium by evaluating learners' quiz scores in each module/session. Each was evaluated using a Media Comparison Study (MCS) model and the unified theory of acceptance and use of technology (UTAUT), a technology acceptance model. The key to effective m-learning lies in the application of instructional design methodologies to its development (Williams, 2009). Simply placing the lecture presentations and other reference materials on a mobile device, as in Moore's (2011) later study, is insufficient and "does not make for an instructionally sound classroom environment - virtual or not" (Williams, 2009, p. 45). Williams' (2009) quasi-experimental, pre-test, post-test study design involved a sample of 180 business information systems students. Face-to-face training participants performed significantly better (9\%) than m-learners (Williams, 2009).

In 2007, Merrill Lynch piloted a mobile learning program called GoLearn. During the pilot, three Merrill Lynch University (MLU) courses were offered via Blackberry to over 2,100 investment bankers and support staff over seven weeks (Brown \& Haag, 2011) to compare the effectiveness of m-learning to traditional e-learning (Stone, 2010). The goals of the pilot were to:

- Deliver m-learning that was as effective as e-learning, with effectiveness measured by learner test scores.

- Obtain $25 \%$ participation of the target sample group.

- Attain a $10 \%$ higher completion rate in $10 \%$ less time than learners trained via alternate methods (Brown \& Haag, 2011).

Overall, the outcomes exceeded the goals of the pilot. Learners obtained higher scores in half the time, and the mobile learners completed their training twenty days earlier than those who trained via MLU (Brown \& Haag, 2011, p. 15).

Brown, Haag (2011) and their Advanced Distributed Learning Team realized that senior management utilized the mobile training content the most. In the pilot, 317 employees completed over 704 training courses, and mobile learners achieved a $12 \%$ higher completion rate in 30\% less time than the control group. Over $60 \%$ of the 2,100 employees accessed mobile learning content at least once during the seven-week pilot (Brown \& Haag, 2011). The pilot group also gained approximately 4,270 hours of extra productivity by completing their training via mobile device (Stone, 2010).

As part of the Merrill Lynch pilot, a survey was distributed to participants and 170 responded. All respondents stated that they would complete mobile learning in the future. Over $75 \%$ of the respondents praised the mobile training for its convenience, effective time management, and the ability to receive training without distractions. Due to the massive success of their pilot, Merrill Lynch expanded their mobile training offerings to approximately 22,000 mobile 
devices (Brown \& Haag, 2011; Stone, 2010).

In many situations, learners will have very strong preferences for one training modality or another. Yet, despite preferences, it has been found that learners' perceptions of usefulness, ease of use, and societal norms are positively correlated with their adoption rates of mobile training. Additionally, those m-learning adoption rates are not affected by demographic characteristics, such as gender and age (Tan, Ooi, Sim, \& Phusavat, 2011).

Input method is one factor that influences adoption rates of asynchronous mobile learning. When training involves learners making some contribution to a training forum, audio input resulted in increased learner perception of usefulness and ease of use, both of which are significant factors for adoption of mobile learning (Chang, 2010).

Little (2012) and Ramsay and Terras (2012) suggested best practices in m-learning design and deployment while presenting some challenges. The first challenge is that mobile learners need superior focus and attentional control in order to be effective learners in physical environments that may not be conducive to learning. The potential for distraction caused by social media places significant added strain on learners' attention (Terras \& Ramsay, 2012). Another challenge is that in order to offer effective, user-accepted m-learning, new technology, techniques, and interoperability standards are needed. Previously accepted instructional design standards must also be revisited and aligned with organizational objectives (Little, 2012).

\subsection{Statement of the Problem}

There is little academic or practitioner literature on the impact of learner preference on performance. Yet, in practice, learner preference is a significant factor that managers and organizational training and development professionals consider when investing in training, and selecting the training delivery method. One groundbreaking recent study found the three primary training modalities: FTF, e-learning, and m-learning are equally effective. The same study encouraged managers to focus on other factors, such as cost and deployment speed, when selecting a training mode. (Paul, 2014) Yet, in practice managers do consider another factor in when choosing what training type to offer. Managers often consider learner preference for the training delivery method. Many learners will emphatically insist that they learn better in-person or online. Since it's already been determined that the training modalities are equally effective (Paul, 2014), it must now be determined whether learner preference influences their performance. This study fills a gap in the existing knowledge base by determining whether offering training in learners' preferred delivery method impacts their performance.

\section{Research Design}

This research explored the learners' preference for and performance in e-learning, m-learning, in and FTF training to determine whether learners perform better in training modules of their preferred format. The experiment required that each study participant complete a training module in one of the three modalities. Participants completed pre- and post-assessments to gauge knowledge gained and evaluate their performance through each delivery method. 
Questionnaires were also completed to capture learner training preferences and demographics. All training modules used in this study included key elements of effective instructional design. These media-rich modules incorporated audio, video, text, and engaging interactions between the learner and the module (Liu, Liao, \& Peng, 2005).

This study sought to answer one main research question: Do learners perform differently in training modules of their preferred format? The independent variables in this experiment were the training modality utilized and the preferred method of training delivery, of which there were three types examined: e-learning, m-learning, and FTF. The dependent variable was the change in score between pre- and post-assessment. For statistical testing in this study, levels of significance (alpha $=0.05$ ) were reported in findings along with $\mathrm{p}$-values. This study tested the following hypotheses:

$\mathrm{H}_{0}$ : There is no difference in training performance between learners who were taught in their preferred format and those who were not taught in their preferred format.

H1: There is a difference in training performance between learners who were taught in their preferred format and those who were not taught in their preferred format.

Learner performance was measured as the change in score between pre- and post-assessment. Regarding the differential performance by learner training preference, this experiment tested the hypothesis that learner training preference does not impact performance.

\section{Methodology}

All learners in this study complete the same four steps. First, learners completed a 10-question pre-assessment to gauge their level of knowledge on the training topic. These pre-assessment scores also served as a baseline in determining the change in scores, or amount learned, between pre- and post-assessment. Pre-assessment and post-assessment questions were different to avoid programming responses but were constructed as a split half instrument totaling twenty questions demonstrated to measure learner performance.

For the second step, learners completed a brief training module. The multimedia training module was published to Blackboard in both mobile and e-learning formats. The training content, pre- and post-assessments, and survey were made available in Blackboard as part of a new course to which all study participants were enrolled. Participants who took the training from a desktop computer completed the standard e-learning module. Those who accessed the training from a mobile device (e.g.: smartphone, tablet, or laptop) completed the training module formatted for viewing on mobile devices. Learners in the FTF group received live training and complete the assessments and survey in hardcopy form. The training content and duration were the same for all study groups despite the different methods of delivery.

For the third step, learners completed a post-assessment in the same format as the pre-assessment with different questions that measured the same constructs. All learners completed the four steps of the study in sequence. Learners completed each assessment only once.

For the fourth step, participants completed a survey questionnaire to capture learner 
preference, demographic data, past experience with e- and m-learning, as well as feedback about their experience in the training module. The survey questionnaire was largely based on Wang's E-learning Satisfaction Survey (Wang Y.-S. , 2003).

\subsection{Sample}

The sample for this experiment was comprised of 103 business students. The study utilized a non-random, convenience sampling approach (Cooper \& Schindler, 2011). As Bryman (2012) stated "In the field of organizational studies it has been noted that convenience samples are very common and indeed are more prominent than samples based on probability sampling." Adler and Clark (2011) reported that 97\% of sociological articles published between 2006 and 2008 were based on convenience sampling, and according to Iaonnidis (2005), as much as $90 \%$ of all published medical research involved neither large samples nor randomized studies(Ioannidis, 2005).

For this study, seven business classes were identified by the researcher. Each class was assigned a treatment: FTF, e-learning, or m-learning. The sample group $(\mathrm{N}=103)$ was comprised of undergraduate and graduate business students enrolled at comprehensive university in Maryland. All of the participants were over 18 years old. There were 64 women and 39 men in this sample. Eighty-two percent were employed at least part time, and all academic classifications were represented in the sample. Students were only allowed to participate in the study once in only one of the three experimental groups. The sample excludes any duplicates.

\subsection{Learner Preference}

The 103 participants in this study were asked via survey questionnaire "How would you prefer to receive training?" Their responses indicated that despite showing no significant difference in performance among the training modalities, the majority of learners, $54 \%$, still preferred traditional FTF instruction, while $42 \%$ preferred participating in training electronically. Of the 103 participants, 29\% indicated that they would prefer to receive training on a mobile device. This is nearly three times the number of learners who preferred standard e-learning on a desktop computer. The four percent of participants who responded "Other" commented that they would prefer multiple methods of training delivery.

One prior study indicated that despite other factors including training preference, there was no significant difference in learner performance among the three training modalities (Paul, 2014). To further investigate whether an interaction exists between training preference and performance, a two-way ANOVA was performed. Table 4 shows the training groups' performance based on training preference. Learners who prefer e-learning learned more despite training modality, with a mean change in score of 38.46. Learners who prefer e-learning also earned the highest mean post-assessment score, 85.38. 


\section{Ml Macrothink}

International Journal of Learning and Development ISSN 2164-4063 2016, Vol. 6, No. 3

Table 1. Descriptive Statistics of Training Preference, Method, Post-Assessment Score, and Change in Score

\begin{tabular}{|c|c|c|c|c|}
\hline Training Method & Training & Mean Change & Mean & $\mathbf{N}$ \\
\hline \multirow[t]{4}{*}{ FTF } & Other & 50.00 & 100.00 & 1 \\
\hline & FTF & 28.80 & 81.60 & 25 \\
\hline & M-Learning & 11.11 & 56.67 & 9 \\
\hline & Total & 24.86 & 75.71 & 35 \\
\hline \multirow[t]{5}{*}{ E-Learning } & Other & 10.00 & 70.00 & 1 \\
\hline & FTF & 30.00 & 75.00 & 22 \\
\hline & E-Learning & 37.50 & 85.83 & 12 \\
\hline & M-Learning & 37.14 & 90.00 & 7 \\
\hline & Total & 32.86 & 80.48 & 42 \\
\hline \multirow[t]{5}{*}{ M-Learning } & Other & 30.00 & 85.00 & 2 \\
\hline & FTF & 21.11 & 91.11 & 9 \\
\hline & E-Learning & 50.00 & 80.00 & 1 \\
\hline & M-Learning & 20.71 & 85.00 & 14 \\
\hline & Total & 22.69 & 86.92 & 26 \\
\hline \multirow[t]{5}{*}{ Total } & Other & 30.00 & 85.00 & 4 \\
\hline & FTF & 28.04 & 80.54 & 56 \\
\hline & E-Learning & 38.46 & 85.38 & 13 \\
\hline & M-Learning & 21.67 & 77.67 & 30 \\
\hline & Total & 27.57 & 80.49 & 103 \\
\hline
\end{tabular}

\section{Analysis of Results}

The test of between-subjects effects on change in score resulted in no main effect for training preference, training method or interaction; $p>0.05$ for all three. See Table 5. A similar test 
was conducted to identify an effect on post-assessment score. There were no main effects for training preference or training method; $p>0.05$. However, there was a statistically significant interaction between training preference and training method on post-assessment performance; $p=0.045$. See Table 3 . This suggeststhat delivering instruction via learners' preferred training method could impact their training performance.

Table 2. Two-Way ANOVA for Preference, Method, and Change in Score

\begin{tabular}{|l|l|}
\hline Source & Sig. \\
\hline Training Method & .881 \\
\hline Preference & .456 \\
\hline Training Method * Preference & .353 \\
\hline
\end{tabular}

Table 3. Two-Way ANOVA for Preference, Method, and Post-Assessment Score

\begin{tabular}{|l|l|}
\hline Source & Sig. \\
\hline Training Method & .792 \\
\hline Preference & .756 \\
\hline Training Method * Preference & .045 \\
\hline
\end{tabular}

Of the sample of 103 study participants, 51, or $49.5 \%$ were trained in their preferred training format (PTM). Fifty-two, or 50.5\%, were not trained in their preferred format (non-PTM). The the PTM group, scored better on the pre-assessment and post-assessment than the non-PTM group. See Table 4. Training Performance Statistics for PTM and Non-PTM Groups They also high a greater change in score, indicating that they learned more and performed better based on the training intervention.

Table 4. Training Performance Statistics for PTM and Non-PTM Groups

\begin{tabular}{|l|l|l|l|l|}
\hline $\begin{array}{l}\text { Preferred Training } \\
\text { Method }\end{array}$ & N & $\begin{array}{l}\text { Mean } \\
\text { Pre-Assessment }\end{array}$ & $\begin{array}{l}\text { Mean } \\
\text { Post-Assessment }\end{array}$ & $\begin{array}{l}\text { Mean } \\
\text { Change in } \\
\text { Score }\end{array}$ \\
\hline Non-PTM & 52 & 51 & 78 & 27 \\
\hline PTM & 51 & 55 & 84 & 29 \\
\hline
\end{tabular}




\section{Grand Total}

103

53

80

28

To test the study's hypothesis, a t-test was conducted to evaluate whether a significant difference exists in post assessment scores when learners are taught in their PTM. The mean post assessment score of the PTM group was not significantly different from the scores of those in the non-PTM group; $\mathrm{p}=0.337$. See

Table 5. An additional t-test was conducted to evaluate whether a difference exists in the change in score between the PTM group and non-PTM groups from the pre-to post-assessment. However, the difference in change in score was not statistically significant; $\mathrm{p}=0.672$

Table 5. Independent Samples T-Test for PTM and Non-PTM Post-Assessment

\begin{tabular}{|l|l|l|l|l|l|l|}
\hline \multicolumn{2}{|c|}{} & \multicolumn{5}{|l|}{ t-test for Equality of Means } \\
\cline { 3 - 7 } & t & df & $\begin{array}{l}\text { Sig. } \\
(2-t a i l e d)\end{array}$ & $\begin{array}{l}\text { Mean } \\
\text { Difference }\end{array}$ & $\begin{array}{l}\text { Std. Error } \\
\text { Difference }\end{array}$ \\
\hline Pre-Assessment & $\begin{array}{l}\text { Equal variances } \\
\text { assumed }\end{array}$ & -.965 & 101 & .337 & -3.940 & 4.082 \\
\hline
\end{tabular}

Table 6. Independent Samples T-Test for PTM and Non-PTM Change in Score

\begin{tabular}{|l|l|l|l|l|l|l|}
\hline \multicolumn{2}{|c|}{} & \multicolumn{5}{|l|}{ t-test for Equality of Means } \\
\cline { 2 - 7 } & $\mathrm{t}$ & df & $\begin{array}{l}\text { Sig. } \\
(2-\text { tailed })\end{array}$ & $\begin{array}{l}\text { Mean } \\
\text { Difference }\end{array}$ & $\begin{array}{l}\text { Std. Error } \\
\text { Difference }\end{array}$ \\
\hline Change in Score & $\begin{array}{l}\text { Equal variances } \\
\text { assumed }\end{array}$ & -.424 & 101 & .672 & -2.089 & 4.921 \\
\hline
\end{tabular}

\section{Conclusion}

This study found no significant difference in training performance between learners who were trained in their preferred training method and those who were not. This information is valuable for organizational training professionals who must select which modality to utilize for their employees' training. Prior research has shown that the three training modalities are of equal effectiveness (Paul, 2014). This study supports Russell's No Significant Difference Phenomenon (1999) by establishing that whether training is delivered in FTF, e-learning or mobile learning format, it will be equally effective for all learners whether they prefer that 
format or not.

Therefore, when evaluating which training modality to invest in, organizational training professionals should base their decisions not on effectiveness or learner preference, but on other factors. Those factors include but are not limited to cost, deployment time, and ease of implementation and revision. Further research should be conducted to explore these factors and how they differ among the training modalities.

\section{References}

Abas, Z. W., Peng, C. L., \& Mansor, N. (2009). A Study of Learner Readiness for Mobile Learning at Open University Malaysia. IADIS International Conference Mobile Learning (pp. 151-157). Barcelona: International Association for the Development of the Information Society.

Ally, M. (2009). Mobile Learning: Transforming the Delivery of Education and Training. Edmonton: AU Press.

American Society for Training \& Development. (2013). Going Mobile: Creating Practices That Transform Learning. Alexandria: ASTD Research.

American Society for Training and Development. (2006). Delivering Training: Module 2. Alexandria: ASTD Press.

Anderson, C. (2014, July). E-Learning Reaches a Milestone. Chief Learning Officer, pp. 44-46.

Barron, J. M., Berger, M. C., \& Black, D. A. (1999). Do Workers Pay for On-the-Job Training? The Journal of Human Resources, 235-252.

Bersin, J. (2014, February 4). Spending on Corporate Training Soars: Employee Capabilities Now a Priority. Retrieved from Forbes.com: http://www.forbes.com/sites/joshbersin/2014/02/04/the-recovery-arrives-corporate-training-s pend-skyrockets/

Bolman, L. G., \& Deal, T. E. (2008). Reframing Organizations: Fourth Edition. San Francisco: John Wiley \& Sons, Inc.

Brown, J., \& Haag, J. (2011). ADL Mobile Learning Handbook. Washington, DC: Advanced Distributed Learning.

Burgess, J. R., \& Russell, J. E. (2003). The Effectiveness of Distance Learning Initiatives in Organizations. Journal of Vocational Behavior, 289-303.

Business and Legal Resources. (2011, March 14). Advantages and Disadvantages of Classroom Training. Retrieved from HR.BLR.com: http://hr.blr.com/HR-news/Staffing-Training/Employee-Manager-Training/Advantages-and-D isadvantages-of-Classroom-Training 


\section{MInstitute ${ }^{\text {Much }}$}

International Journal of Learning and Development ISSN 2164-4063

Carruth, P. J., \& Carruth, A. K. (2013). Educational and Financial Impact of Technology on Workforce Development. American Journal of Business Education, 513 - 520.

Chang, C.-K. (2010). Acceptability of an Asynchronous Learning Forum on Mobile Devices. Behaviour \& Information Technology, 23-33.

Cooper, D. R., \& Schindler, P. S. (2011). Business Research Methods, 11th Edition. New York: McGraw-Hill/Irwin.

DeRouin, R. E., Fritzsche, B. A., \& Salas, E. (2005). E-Learning in Organizations. Journal of Management, 920-940.

Elwart, S. (2013, January 13). Information Overload Making Your Head Explode. Retrieved July 26, 2013, from http://www.wnd.com/2013/01/information-overload-making-your-head-explode/

Gaither, K. A. (2009). Comparing the Perceived Effectiveness of E-Learning and Traditional Training in the Business Environment. Ann Arbor: ProQuest.

Ioannidis, J. P. (2005, August 30). Why Most Published Research Findings are False. Retrieved from PLOSMedicine.org: http://www.plosmedicine.org/article/info\%3Adoi\%2F10.1371\%2Fjournal.pmed.0020124

Kelley, E. (2014, July 14). Why Employee Development is Important. Retrieved from Business2BusinessCommunity.com:

http://www.business2community.com/human-resources/employee-development-important-09 38005?cm_mmc=membership-_-buzz-_-email-_-jm-2014.07.21.TheBuzz\&vendor=bronto\&c ategory=email\&placement=marketing\&email=tyechiapaul\%40gmail.com\&utm_medium=em ail\&utm_source=br

Kruse, K. (2004, November 14). What are "Synchronous" and "Asynchronous" Training? Retrieved July 26, 2013, from MSMC.la.edu: http://www.msmc.la.edu/include/learning_resources/online_course_environment/async_sync. pdf

Little, B. (2012). Effective and Efficient Mobile Learning: Issues and Tips for Developers. Industrial and Commercial Training, 402-407.

Liu, S.-H., Liao, H.-L., \& Peng, C.-J. (2005). Applying the Technology Acceptance Model and Flow Theory to Online E-Learning Users' Acceptance Behavior. Issues in Information Systems, 175-181.

Lundquist, T. (2009). Profiscience Partners Download Center. Retrieved July 26, 2013, from www.profiscience.com: http://www.profiscience.com/Downloads.aspx

Meister, J. C. (1998, November). Ten Steps for Creating a Corporate University. Training \& Development, pp. 38-42.

Moore, B. M. (2011). Evaluating and Blending Multimedia Mobile Applications into Technical Training. Ann Arbor: ProQuest, LLC. 


\section{I Macrothink}

International Journal of Learning and Development ISSN 2164-4063 2016, Vol. 6, No. 3

O'Dell, T. (2009). Generational Differences in Satisfaction with E-Learning in a Corporate Learning Environment. Ann Arbor: ProQuest, LLC.

Paul, T. V. (2014). An Evaluation of the Effectiveness of E-Learning, Mobile Learning, and Instructor-Led Training in Organizational Training and Development. Hampton: ProQuest.

Phillips, J. J. (2003). Return on Investment in Training and Performance Improvement Programs Second Edition. New York: Butterworth - Heinemann.

Rao, S. R. (2011). Global E-Learning: A Phenomenological Study. Fort Collins: Colorado State University.

Roberts, B. (2012, August). From E-Learning to Mobile Learning. HR Magazine, pp. 61-65.

Russell, T. L. (1999). The No Significant Difference Phenomenon. Raleigh: North Carolina State University.

Stacy, M., \& Taylor, R. P. (2010, September 29). Delivering a Transformational L\&D Strategy. Retrieved July 25, 2013, from www.slideshare.net: http://www.slideshare.net/humancapitalmedia/delivering-a-transformationalld

Stern, G. M. (2011, May 27). Company Training Programs: What are they Really Worth? Retrieved July 25, 2013, from CNN Money: http://management.fortune.cnn.com/2011/05/27/company-training-programs-what-are-they-re ally-worth/

Stone, T. (2010). A Guide for CLOs and Training Managers. Rochester: Element K Corporation.

Strother, J. (2002). An Assessment of the Effectiveness of E-Learning in Corporate Training Programs. International Review of Research in Open and Distance Learning.

Tan, G. W.-H., Ooi, K.-B., Sim, J.-j., \& Phusavat, K. (2011). Determinants of Mobile Learning Adoption: An Empirical Analysis. Journal of Computer Information Systems, 82-91.

Terras, M. M., \& Ramsay, J. (2012). The Five Central Psychological Challenges Facing Effective Mobile Learning. British Journal of Educational Technology, 820-832.

Walvoord, B. E. (2010). Assessment Clear and Simple: A Practical Guide for Institutions, Departments, and General Education (2nd ed.). San Francisco: Jossey-Bass.

Wang, G. G., Sun, J. Y., Li, J. J., \& Xuejun, Q. (2008). Exploring the Corporate University Phenomenon. Academy of Human Resource Development International Research Conference. Panama City: Academy of Human Resource Development.

Wang, Y.-S. (2003). Assessment of Learner Satisfaction with Asynchronous Electronic Learning Systems. Information and Management, 75-86.

Welsh, E. T., Wanberg, C. R., Brown, K. G., \& Simmering, M. J. (2003). E-learning: Emerging Uses, Empirical Results, Future Directions. International Journal of Training and 


\section{Macrothink \\ International Journal of Learning and Development \\ ISSN 2164-4063 2016, Vol. 6, No. 3}

Development, 245-258.

Williams, P. W. (2009). Assessing Mobile Learning Effectiveness and Acceptance. Ann Arbor: ProQuest.

\section{Copyright Disclaimer}

Copyright for this article is retained by the author(s), with first publication rights granted to the journal.

This is an open-access article distributed under the terms and conditions of the Creative Commons Attribution license (http://creativecommons.org/licenses/by/3.0/). 